\title{
INSERÇÃO PROFISSIONAL: APRENDIZAGENS, DESAFIOS E IMPLICAÇÕES PARA A FORMAÇÃO E PRÁTICA PEDAGÓGICA NA EDUCAÇÃO INFANTIL
}

\author{
Diana Aguiar Salomão ${ }^{1}$, Sandy Lima Costa $^{2}$, Francisco Mirtiel Frankson Moura Castro ${ }^{3}$ \\ ${ }^{1}$ Mestranda em Educação pelo Programa de Pós-Graduação em Educação da Universidade Estadual do Ceará - \\ PPGE/UECE. Atualmente, é professora efetiva da Rede Municipal de Ensino de Fortaleza, Educação Infantil. ORCID iD: \\ https://orcid.org/0000-0003-0638-8547. E-mail: diana salomao@hotmail.com \\ ${ }^{2}$ Mestranda em Educação pelo Programa de Pós-Graduação em Educação da Universidade Estadual do Ceará - \\ PPGE/UECE. Bolsista, na Pós-Graduação, da Coordenação de Aperfeiçoamento de Pessoal de Nível Superior - CAPES. \\ ORCID iD: https://orcid.org/0000-0003-3028-7949. E-mail: sandy.lima@aluno.uece.br \\ ${ }^{3}$ Pós-Doutor em Educação pela Universidade Federal do Ceará - UFC. Professor Assistente, do Setor de Estudos, \\ Metodologia e Pesquisa em Educação da Universidade Estadual do Ceará - UECE e docente do Programa de Pós- \\ Graduação em Educação PPGE/UECE. ORCID iD: https://orcid.org/0000-0002-8685-9857. E-mail: \\ mirtielfrankson@gmail.com
}

\section{RESUMO}

Este artigo discute a inserção profissional, objetivando compreender que aprendizagens, desafios e implicações essa fase da formação docente tem para a prática pedagógica de uma pedagoga que atua na Educação Infantil na rede municipal de ensino de Fortaleza - Ceará. A pesquisa, desenvolvida em 2019, utilizou a abordagem qualitativa, realizando um estudo de caso. Para a produção de dados, foi utilizado um questionário eletrônico misto (fase I da pesquisa), e a entrevista narrativa (fase II da pesquisa). Para a análise, foi adotado o método de Análise Textual Discursiva. O embasamento teórico deste estudo recorreu a estudos relativos à inserção profissional (MARCELO GARCIA, 1999; HUBERMAN, 2007) e à aprendizagem da docência (OLIVEIRA-FORMOSINHO, 2002; TARDIF, 2002; PLACCO; SOUZA, 2006; PIMENTA, 2009), especificamente no contexto da Educação Infantil. Os dados revelaram que a docente vivenciou paralelamente os sentimentos de sobrevivência e descoberta da profissão; a aprendizagem da docência partiu de iniciativa pessoal pela busca contínua por conhecimentos, além de interação com os pares e a experiência em sala; e a falta de apoio institucional foi elencada como um dos principais desafios para a inserção na profissão. Concluímos, portanto, que é necessário planejar e implementar políticas públicas educacionais voltadas especificamente para o acompanhamento sistematizado de professores iniciantes, visando à promoção de processos institucionais de indução que supram as necessidades formativas dessa etapa da formação profissional docente. Além disso, ratificamos a necessidade de ampliar a colaboração entre escola e universidade para favorecer a aprendizagem da docência por meio de experiências que promovam a articulação entre teoria e prática.

Palavras-chave: Inserção profissional. Professora iniciante. Educação Infantil. Aprendizagem da docência. Formação.

\section{PROFESSIONAL INSERTION: LEARNING, CHALLENGES AND IMPLICATIONS FOR TRAINING AND PEDAGOGICAL PRACTICE IN EARLY CHILDHOOD EDUCATION}

\section{ABSTRACT}

This article discusses professional insertion, aiming to understand what learning, challenges and implications this phase of teacher education has for the pedagogical practice of a pedagogue who works in Early Childhood Education in the municipal education network of Fortaleza - Ceará. The research, developed in 2019, used the qualitative approach, carrying out a case study. For data production, a mixed electronic questionnaire (phase I of the research) and a narrative interview (phase II of the research) were used. For the analysis, the Discursive Textual Analysis method was adopted. The theoretical basis of this study used studies related to professional insertion (MARCELO GARCIA, 1999; HUBERMAN, 2007) and 
teaching learning (OLIVEIRA-FORMOSINHO, 2002; TARDIF, 2002; PLACCO; SOUZA, 2006; PIMENTA, 2009), specifically in the context of Early Childhood Education. The data revealed that the teacher experienced, in parallel, the feelings of survival and discovery of the profession; teaching learning came from personal initiative through the continuous search for knowledge, in addition to interaction with peers and classroom experience; and the lack of institutional support was listed as one of the main challenges for entering the profession. We conclude, therefore, that it is necessary to plan and implement public educational policies aimed specifically at the systematic monitoring of beginning teachers, aiming at promoting institutional processes of induction that meet the training needs of this stage of professional teacher training. In addition, we ratify the need to expand collaboration between school and university to favor teaching learning through experiences that promote the articulation between theory and practice.

Keywords: Professional insertion. Beginning teacher. Early Child education. Teaching learning. Formation.

\section{INSERCIÓN PROFESIONAL: APRENDIZAJE, DESAFÍOS E IMPLICACIONES PARA LA FORMACIÓN Y LA PRÁCTICA PEDAGÓGICA EN LA EDUCACIÓN INFANTIL}

\section{RESUMEN}

Este artículo analiza la inserción profesional, con el objetivo de comprender qué aprendizajes, desafíos e implicaciones tiene esta fase de la formación docente para la práctica pedagógica de un pedagogo que trabaja en Educación Infantil en la red educativa municipal de Fortaleza - Ceará. La investigación, desarrollada en 2019, utilizó el enfoque cualitativo, realizando un estudio de caso. Para la producción de datos se utilizó un cuestionario electrónico mixto (fase I de la investigación) y una entrevista narrativa (fase II de la investigación). Para el análisis se adoptó el método de Análisis Textual Discursivo. La base teórica de este estudio utilizó estudios relacionados con la inserción professional (MARCELO GARCIA, 1999; HUBERMAN, 2007) y la enseñanza aprendizaje (OLIVEIRA-FORMOSINHO, 2002; TARDIF, 2002; PLACCO; SOUZA, 2006; PIMENTA, 2009), específicamente en el contexto de la Educación Infantil. Los datos revelaron que el docente vivió, en paralelo, los sentimientos de supervivencia y descubrimiento de la profesión; la enseñanza del aprendizaje surgió de la iniciativa personal mediante la búsqueda continua de conocimientos, además de la interacción con los compañeros y la experiencia en el aula; y la falta de apoyo institucional fue catalogado como uno de los principales desafíos para ingresar a la profesión. Concluimos, por tanto, que es necesario planificar e implementar políticas educativas públicas dirigidas específicamente al seguimiento sistemático de los docentes principiantes, con el objetivo de promover procesos institucionales de inducción que atiendan las necesidades formativas de esta etapa de la formación profesional docente. Además, ratificamos la necesidad de ampliar la colaboración entre la escuela y la universidad para favorecer la enseñanza aprendizaje a través de experiencias que promuevan la articulación entre teoría y práctica.

Palabras clave: Inserción professional. Docentes principiantes. Educación infantil. Enseñanza aprendizaje. Formación.

\section{INTRODUÇÃO}

Este estudo explicita discussões sobre a inserção profissional docente no âmbito da Educação Infantil, considerando os desafios, as aprendizagens e as implicações para a formação e para a prática pedagógica. Trata-se de um estudo que foi desenvolvido junto à disciplina "Formação e Desenvolvimento Profissional Docente" em um curso de Pós-Graduação em Educação stricto sensu do estado do Ceará, no segundo semestre do ano de 2019, que teve como um de seus conteúdos e unidade de estudo o tema formação e inserção profissional de professores iniciantes, temática essa que instigou, por exemplo, a produção e discussão reflexiva de cartas narrativas/descritivas da inserção profissional dos estudantes de mestrado matriculados neste componente curricular, e a elaboração desta pesquisa pelos autores deste artigo.

A formação de professores é uma temática que vem alcançando crescente notoriedade ao longo dos últimos anos no cenário brasileiro, uma vez que esta implica, dentre outras dimensões, diretamente na qualidade da prática pedagógica, situação que requer maior atenção e reflexões em várias esferas, contextos e espaços educacionais. No 
âmbito da Educação Infantil, o estudo sobre a formação de docentes se evidencia como central, em virtude de uma série de aspectos, entre os quais se cita que essa etapa da Educação Básica teve menor visibilidade no cenário histórico das políticas públicas educacionais do Brasil, tanto nas condições físicas como pedagógicas, e também de valorização profissional, daí a centralidade e a relevância desta produção.

Ademais, a opção em nos debruçarmos sobre o processo formativo de docentes que atuam na Educação Infantil refere-se à aproximação profissional dos autores com essa etapa da Educação Básica e a compreensão de que a docência nesse âmbito é permeada por desafios e particularidades que exigem do professor o conhecimento para educar e cuidar, de forma indissociável, de bebês (crianças de 0 a 18 meses), de crianças bem pequenas (crianças de 0 a 18 meses) e de crianças pequenas (crianças entre 4 anos e 6 anos e 11 meses) (BRASIL, 2009a).

Dessa forma, enquanto docentes pesquisadores que conhecem e experienciam essa realidade, consideramos necessário demandar atenção sobre a inserção profissional docente na Educação Infantil, especialmente ao ser pesquisado um contexto específico vivenciado por uma jovem professora na rede municipal de ensino do município de Fortaleza Ceará.

Nessa perspectiva, consideramos importante destacar que, neste estudo, estamos vinculando a inserção profissional docente estritamente à categoria tempo, conforme proposto por Huberman (2007) ao tratar do ciclo de vida dos professores. Desse modo, modalizamos a inserção profissional docente como o momento de iniciação na carreira, que marca a passagem de estudante para profissional, sendo um dos períodos que constitui o ciclo de vida do professor.

O período de iniciação profissional docente é uma das fases do "processo de aprender a ensinar" ${ }^{\prime 1}$, permeado, na maioria das vezes, por desafios, sofrimento psíquico, insegurança, solidão e choque de realidade, aspectos que produzem as principais marcas da identidade e do estilo profissional dos

\footnotetext{
${ }^{1}$ Para Marcelo Garcia (1999), a formação dos professores, também denominada de processo de aprender a ensinar, perpassa diferente fases, sendo elas a pré-formação, a formação inicial, a inserção profissional e a formação permanente/continuada.
}

professores ao longo de sua carreira (MARCELO GARCIA, 1999).

O contato inicial com as situações da sala de aula perdura até os três primeiros anos e é marcado por um estado de sobrevivência e de descoberta. A sobrevivência se traduz no aspecto que chamamos de "choque de realidade", ou seja, é a experiência inicial com a complexidade da situação profissional, que envolve aspectos como a constante preocupação consigo e com seu trabalho, a distância entre a teoria da universidade e a prática escolar, os desafios com a falta de recursos e infraestruturas inadequadas, as dificuldades para lidar com a indisciplina dos alunos, dentre outros aspectos que se constituem como desafios encontrados pelo professor iniciante (HUBERMAN, 2007).

Por outro lado, a entrada na carreira também é marcada pelo sentimento de descoberta, ou seja, de expectativas, um entusiasmo inicial, experimentação de ter uma turma sob sua responsabilidade. Em muitas vezes, esse sentimento da descoberta, segundo Huberman (2007), ajuda a suportar o da sobrevivência, uma vez que esses dois sentimentos são vividos paralelamente no início da docência. Ambos os sentimentos são perpassados pela exploração no contexto do ensino, podendo ser fácil ou problemática, mas geralmente limitada devido a parâmetros impostos pela instituição escolar, como, por exemplo, contato com poucas turmas.

Especificamente sobre a inserção profissional docente na Educação Infantil, há constatações equivocadas de que essa etapa é a mais fácil da Educação Básica e que, consequentemente, exige menos experiência e qualificação profissional, o que acarreta a destinação de professores iniciantes às turmas de Educação Infantil. No entanto, atuar na Educação Infantil é um grande desafio aos professores principiantes, pois exige habilidades singulares e conhecimentos específicos que, na maioria das vezes, não são adquiridos na formação inicial (CARDOSO, 2013).

A esse respeito, ressaltamos que a formação inicial de professores para atuação na Educação Infantil foi consolidada no curso de Licenciatura em Pedagogia a partir da aprovação das Diretrizes Curriculares Nacionais para o Curso de Pedagogia, por meio da Resolução CNE/CP no 1, de 15 de maio de 2006 (BRASIL, 2006), e que, além dessa atribuição, o curso também incorporou a responsabilidade de formar 
professores para atuarem nos anos iniciais do Ensino Fundamental, nos cursos de Ensino Médio - na modalidade Normal -, na Educação de Jovens e Adultos - EJA - e de formar gestores e especialistas em assuntos pedagógicos para trabalharem na área educacional.

A partir desse amplo e diversificado rol de atribuições destinado ao curso de Licenciatura em Pedagogia, refletimos, em destaque, sobre a sua capacidade de contemplar a especificidade do fazer docente na Educação Infantil, considerando que as concepções, finalidades e organização do processo educativo nessa etapa envolve uma preocupação com a qualidade dos espaços, tempos e materiais para assegurar 0 educar e o cuidar de forma indissociável às crianças de 0 a 5 anos de idade (BRASIL, 2009b).

Diante disso, corroboramos Gatti e Barreto (2009) sobre a formação inicial oferecida no curso de Licenciatura em Pedagogia ser frágil para o exercício do magistério na Educação Infantil e, por isso, destacamos a relevância da preocupação com a inserção profissional docente no âmbito da Educação Infantil, ressaltando que a importância e a necessidade de apoio e acompanhamento sistematizado durante esse período expressa uma maior relevância devido às especificidades da docência nessa etapa.

Nesse sentido, assim como a infância passou a ser reconhecida como a fase primordial para o desenvolvimento humano, sendo concebida como o começo da vida em que a atenção dada a esse período pode mudar a vida por inteiro, a inserção profissional docente também precisa incorporar essa relevância. Essa fase de iniciação na carreira pode ser preponderante para a permanência na profissão, para a constituição da identidade docente e para o desenvolvimento profissional. Considerando tais aspectos, é fundamental discutirmos como se dá a formação dos professores responsáveis pela educação intencional e cuidado no começo da vida dos discentes e como eles estão sendo tratados, recebidos e acolhidos no início de suas vidas profissionais.

Nessa direção, ao reconhecer e problematizar a especificidade da primeira etapa da Educação Básica e compreender a importância do início da carreira para o desenvolvimento profissional docente, elaboramos o seguinte questionamento: que aprendizagens da docência, desafios e implicações tem a inserção profissional para a formação e prática pedagógica de uma pedagoga que atua na Educação Infantil?
Diante dessa inquietação, objetivamos, com este estudo, compreender que aprendizagens da docência, desafios e implicações tem a inserção profissional para a formação e prática pedagógica de uma pedagoga que atua na Educação Infantil da rede de ensino municipal de Fortaleza - Ceará. Este texto está organizado em quatro seções: introdução, ora concluída; delineamento metodológico; resultados e discussão, que é organizada em três subseções; e conclusões, seguida das referências que fundamentaram $\mathrm{o}$ estudo. $\mathrm{Na}$ seção seguinte, apresentamos os aspectos metodológicos que foram fundamentais para alcançarmos o objetivo citado.

\section{DELINEAMENTO METODOLÓGICO}

Esta pesquisa foi expressa na abordagem qualitativa e se caracteriza como empírica, tendo em vista a compreensão sobre a aprendizagem da docência, desafios e implicações que tem a inserção profissional para a formação e prática pedagógica de uma docente iniciante na carreira. Configura-se como um estudo de caso (STAKE, 2016), sendo o caso a inserção profissional de uma pedagoga na Educação Infantil. Para Stake (2016), o estudo de caso se caracteriza por abordar a complexidade e particularidade de um único caso, buscando compreendê-lo no âmbito de suas circunstâncias específicas. Nesse sentido, o estudo de caso possibilita a análise detalhada de uma situação, sendo uma parte de um sistema maior.

Ressaltamos que o estudo assegurou os direitos da participante, expressos na Resolução CNS № 510/2016, e seguiu as orientações propostas pela Resolução CNS № 466/2012, referente aos procedimentos éticos necessários em pesquisas envolvendo seres humanos para assegurar o respeito à dignidade humana e à proteção devida à professora pesquisada, como: (I) respeito à liberdade e autonomia da participante; (II) esclarecimentos à participante quanto aos procedimentos da pesquisa, desde questões iniciais até o compromisso de divulgação da mesma; (III) uso do termo de consentimento livre e esclarecido (TCLE) assinado pela participante da pesquisa; (IV) ponderação entre riscos e benefícios; (V) garantia de que danos previsíveis seriam evitados para assegurar o seu bem-estar; (VI) relevância social da pesquisa; (VII) utilização de métodos adequados para responder à questão da pesquisa; (VIII) adequação aos princípios, fatos e fundamentos 
científicos; (IX) utilização de protocolos para garantir a confidencialidade e a privacidade da participante; $(X)$ utilização do material e dos dados produzidos na pesquisa somente para 0 objetivo proposto. Além disso, destacamos que os dados produzidos foram validados pela professora, aspecto recomendado pela Associação Nacional de Pós-Graduação e Pesquisa em Educação (ANPED, 2019).

A produção de dados foi realizada em duas fases. $\mathrm{Na}$ primeira, recorremos ao questionário ${ }^{2}$ eletrônico misto, estruturado no aplicativo Google forms ${ }^{3}$, enviado de 5 a 11 de novembro de 2019, por intermédio do aplicativo de mensagens WhatsApp, para grupos que tinham como integrantes professores da rede municipal de ensino de Fortaleza - Ceará. Esse questionário teve o intuito de identificar os professores dessa rede de ensino que estivessem nos anos iniciais da carreira docente e que manifestassem interesse e disponibilidade em participar da segunda fase da pesquisa, uma entrevista narrativa individual.

Obtivemos 33 respostas, sendo que apenas oito dessas eram advindas de professores que possuíam até três anos de docência. Portanto, considerados iniciantes com base na categoria tempo proposta por Huberman (2007). Como critérios de inclusão para a entrevista narrativa, segunda fase da produção de dados, consideramos: ser pedagogo; atuar na Educação Infantil da rede municipal de ensino de Fortaleza; ter o menor tempo de experiência profissional após a conclusão da licenciatura; e ter aceitado participar da etapa seguinte da pesquisa. Apenas uma docente atendeu a esses critérios.

Em seguida, entramos em contato com a professora, via telefone celular disponibilizado no ato da resposta ao questionário, e marcamos a realização da entrevista narrativa. É válido explicitarmos de que forma fizemos uso da entrevista narrativa e como analisamos os dados obtidos. Este tipo de entrevista possui uma

\footnotetext{
${ }^{2}$ O questionário é um instrumento de produção de dados, sendo um conjunto de perguntas geralmente feitas em papel ou em tela de computador, da mesma forma para todos os participantes da pesquisa, podendo ser obtida uma grande quantidade de respostas (STAKE, 2011).

${ }^{3}$ O Google Forms é um aplicativo do pacote do escritório do Google Drive que possibilita criar e administrar pesquisas. Optamos por esse aplicativo por considerá-lo uma forma fácil e eficaz de acesso aos possíveis colaboradores da pesquisa para obtenção das respostas e por sua praticidade de criação personalizada de formulário. Além disso, a escolha também se deu pelo fato de o mesmo fornecer resumos automáticos das respostas por meio de gráficos e planilhas, favorecendo análise detalhada dos dados da pesquisa.
}

estrutura específica para o seu desenvolvimento, composta por fases e regras, e a sua principal característica é a não diretividade e interferência do pesquisador durante o seu desenvolvimento, pois o seu o intuito é estimular o participante a narrar a história sobre algum acontecimento importante de sua vida pessoal e/ou profissional (JOVCHELOVIC; BAUER, 2002).

Nesse sentido, realizamos a entrevista narrativa seguindo as fases propostas por Jovchelovic e Bauer (2002). Incentivamos a professora participante a narrar o seu processo de inserção profissional docente, destacando aprendizagens, desafios e implicações para a sua formação e prática pedagógica na Educação Infantil por meio da exemplificação de situações que facilitaram e/ou dificultaram os momentos iniciais de sua experiência como professora.

A narrativa possibilita a lembrança sobre o que aconteceu e, por meio dela, as pessoas podem organizar suas experiências e encontrar explicações para acontecimentos e sentimentos, construindo, assim, autoconhecimentos sobre sua história de vida pessoal ou profissional (JOVCHELOVIC; BAUER, 2002). Nessa perspectiva, a narrativa pode ser concebida como uma experiência eminentemente formativa, pois, ao contar os acontecimentos importantes de suas histórias de vida, os sujeitos reconstroem suas trajetórias, incorporando outros significados e aprendizagens. Isso, de certo modo, configura-se como um contexto de formação docente.

Diante de tais pressupostos, buscamos analisar a narrativa da professora participante desta pesquisa por intermédio da Análise Textual Discursiva (ATD), "caracterizada como uma metodologia na qual, a partir de um conjunto de textos ou documentos, produz-se um metatexto, descrevendo e interpretando sentidos e significados que o analista constrói ou elabora a partir do referido corpus" (MORAES, 2003, p. 202). No caso desta pesquisa, o corpus analisado foi a transcrição da entrevista narrativa.

A entrevista narrativa foi gravada, transcrita e enviada por e-mail para a professora participante validá-la. É importante ressaltar que essa investigação considerou e assegurou os princípios éticos gerais previstos para as pesquisas em Educação (ANPED, 2019), pois reconhecemos a possibilidade de a metodologia empregada suscitar, na participante, diversas emoções e lembranças positivas e/ou negativas.

Desse modo, avaliamos, de forma criteriosa, o potencial de risco e desconforto que 
a entrevista narrativa poderia gerar na professora envolvida na investigação, e, com isso, adotamos uma postura ética, a fim de estabelecer uma relação de confiança com ela, amenizando possíveis constrangimentos, e, assim, resguardar sua autonomia, bem-estar e segurança. Assumimos o compromisso de respeito ao relato da participante, evitando gestos e perguntas que poderiam causar transtornos e/ou danos psicológicos, morais ou físicos, e garantimos a confidencialidade dos dados e o seu anonimato.

Além disso, utilizamos o Termo de Consentimento Livre Esclarecido (TCLE), o qual apresentava o objetivo da investigação, os acordos e as informações sobre as condições de participação na pesquisa, o contato dos pesquisadores e os esclarecimentos sobre a possibilidade de os conhecimentos produzidos com o estudo serem publicados, sendo mantido o anonimato com uso de nome fictício, escolhido pela entrevistada. Deste modo, após concordar e assinar com o que estava exposto no TCLE, a professora entrevistada autorizou a gravação e a utilização dos dados provenientes da sua narrativa e escolheu ser identificada por Bia.

Considerando a transcrição da entrevista narrativa - validada pela professora - como o corpus de análise, a ATD foi elaborada a partir de uma triangulação entre os dados produzidos pela narrativa da professora, a fundamentação teórica dos autores referências nas temáticas abordadas nesta investigação e a visão dos pesquisadores. A ATD empreendida nessa investigação foi iniciada pela unitarização do texto produzido pela transcrição da entrevista narrativa, a qual aconteceu por meio de três momentos: fragmentação e codificação do corpus em unidades; reescrita das unidades de modo a construir um significado para cada uma; e atribuição de um nome a cada unidade construída.

Em seguida, partimos para a categorização dessas unidades de análise, classificando-as e combinando-as para buscar compreender os diferentes aspectos de seus sentidos e significados. Organizamos as unidades em conjuntos mais complexos, reunindo-as por significados semelhantes que se relacionavam com a temática e com o objetivo da investigação, formando, assim, as seguintes categorias: inserção profissional docente na Educação Infantil, aprendizagens da docência na inserção profissional, desafios da inserção profissional, implicações da inserção profissional para a formação e prática pedagógica na Educação Infantil.

Neste processo de constituir categorias por meio da contrastação e comparação constante entre as unidades de análise a partir de uma profunda impregnação com os excertos transcritos e a produção de metatextos, emergiram outras compreensões, e com elas definimos outras categorias a serem exploradas e apreciadas na pesquisa, a saber: formação inicial inconsistente, aprendizagem da docência por meio do contato exógeno com a profissão, saberes da experiência, especificidades da docência na Educação Infantil, autoformação, apoio de pares e trabalho colaborativo.

Engajados neste momento analítico de desmonte, auto-organização e de intensa impregnação com o corpus de análise, objetivamos expressar a compreensão atingida por nós (pesquisadores) do fenômeno investigado, revelando o conjunto de significantes do material analisado ao atribuir a eles significados de acordo com os nossos conhecimentos e as abordagens teóricas adotadas. A seguir, com suporte nos excertos descritivos e interpretativos, comunicamos a emergência dos sentidos e dos significados que constituem e fundamentam essa investigação.

\section{RESULTADOS E DISCUSSÃO}

Esta seção, estruturada em três subseções, expõe a análise dos dados e a discussão dos resultados com amparo na caracterização da professora participante e o seu contexto de trabalho nos três primeiros anos de atuação profissional, apresentando discussões sobre sua inserção docente na Educação Infantil com suporte na consideração de desafios, sentimentos, aprendizagens e saberes que marcaram este processo e trouxeram implicações diretas à sua formação, prática pedagógica e interesse em permanecer na profissão, tomando como ponto de reflexão a narrativa da professora entrevistada.

O aporte teórico que norteou a análise dos dados baseou-se nos estudos de Marcelo Garcia (1999); Oliveira-Formosinho (2002); Tardif (2002); Placco e Souza (2006); Huberman (2007) e Pimenta (2009), dentre outros.

Com suporte nas contribuições desses autores, trazemos, nas subseções referentes às unidades de análise, a discussão e interpretação das categorias teóricas que fundamentam esse estudo. 


\section{A INICIANTE NA PROFISSÃO: APRENDIZAGENS DA FORMAÇÃO INICIAL E A IDENTIFICAÇÃO COM A EDUCAÇÃO INFANTIL}

A professora iniciante participante deste estudo tem entre 25 e 35 anos de idade, concluiu Licenciatura em Pedagogia no ano de 2015, em instituição de ensino superior de um estado brasileiro, e iniciou a sua carreira no ano de 2017 como professora substituta na etapa da Educação Infantil, especificamente no Infantil II, numa das instituições da rede municipal de ensino de Fortaleza, na qual atualmente exerce a docência junto de crianças bem pequenas. Vale ressaltar que a opção de trabalhar na Educação Infantil foi uma escolha e não uma condição de única opção.

Enquanto aluna, ainda durante a sua formação inicial, viveu algumas experiências com a prática docente e teve a oportunidade de realizar trabalhos de campo em algumas disciplinas, especialmente no âmbito da Educação Infantil, antes mesmo das disciplinas de Estágio Supervisionado. Segundo Bia, essas experiências pontuais favoreceram 0 encantamento e a identificação com a profissão e com a etapa da Educação Infantil, contudo, quando iniciou de fato sua experiência como professora, sofreu um "choque de realidade", que a fez pensar em desistir e sentir receio sobre sua escolha pela docência, pois narrou:

\begin{abstract}
No início, quando temos uma experiência que é de um dia, dois dias [...] não temos como conhecer e ficamos pensando: será que é isso que realmente eu quero para mim? Quando o tempo vai passando, você vai [...] concretizando, pois é gratificante trabalhar com criança, recebemos muito afeto e percebemos que as crianças têm uma carência de afeto [...] (PROFESSORA BIA).
\end{abstract}

Como podemos perceber no relato, após o "choque de realidade" e com o curso da sua inserção profissional, a identificação com a docência e com a etapa da Educação Infantil foi comprovada principalmente pelo acolhimento e envolvimento afetivo com as crianças, fato este imprescindível para a permanência na carreira. A esse respeito, os estudos de Wallon (GALVÃO,
1995) ressaltam a importância da afetividade na relação entre professor e aluno e a sua contribuição para o aprendizado da profissão e para o processo de ensino e aprendizagem.

Além das experiências com a prática docente em trabalhos de campo durante algumas disciplinas, Bia também vivenciou, concomitante à sua graduação, a experiência de estágio remunerado na Educação Infantil, como assistente de sala em uma instituição particular. Essa inserção no campo profissional foi considerada difícil de início, por ser sua primeira experiência de duração mais prolongada de atuação no âmbito escolar, mas depois se tornou um cenário repleto de aprendizagens da docência.

As experiências acumuladas por Bia com as atividades de prática de ensino desenvolvidas durante e concomitante à sua formação inicial favoreceram a aquisição e o desenvolvimento inicial de saberes da experiência (TARDIF, 2002; PIMENTA, 2009), proporcionando aprendizagens da docência que geraram implicações na sua prática pedagógica, pois passou a refletir e apropriar-se bastante dessas aprendizagens quando se tornou professora. A seguir, destacamos um recorte de sua narrativa, que evidencia as afirmativas anteriores.

[...] na universidade que eu estudava foi montada uma brinquedoteca, então a gente tinha algumas disciplinas que o professor fazia atividades nesse local. Nessa brinquedoteca, a gente recebia crianças e realizava atividades com elas. Naquele espaço, a gente podia, de certa forma, iniciar também a nossa prática [...] lá era o nosso laboratório de aprendizagem, onde fazíamos e vivenciávamos atividades e brincadeiras, atividades de práticas de ensino em diversas disciplinas. [...] foi uma experiência muito boa, porque ela agregou bastante, e muitas das coisas que utilizo na minha sala de aula são desse período em que eu estive como estagiária. Eu 
trabalhei com excelentes professores e aprendi muito com eles (experiência de estágio remunerado)

(PROFESSORA BIA).

A aprendizagem por meio de atividades práticas, apontada por Bia, por meio da observação e da prática no contato exógeno com a profissão (LIMA, 2004), converge com os apontamentos de Placco e Souza (2006, p. 17) sobre a aprendizagem da docência, a qual se dá, também, com base na "[...] interação entre adultos, quando experiências são interpretadas, habilidades e conhecimentos são adquiridos e ações são desencadeadas". Diante do exposto, destacamos a necessidade, inclusive institucional, de se conhecer a trajetória profissional de cada professor e, assim, compreender a constituição de sua identidade docente e de aspectos de sua trajetória formativa, pois, corroborando Marcelo Garcia (1999), o desenvolvimento profissional docente ocorre ao longo da vida e se permeia por fases, que vão constituindo a identidade do professor.

Ademais, inserido em uma condição de aprendiz, “[...] não é possível conceber a aprendizagem do adulto, sobretudo do adulto professor, sem considerar 0 processo de formação identitária" (PLACCO; SOUZA, 2006, p. 23). Desse modo, consideramos que conhecer aspectos sobre a formação inicial da Bia foi de extrema importância para compreendermos como ela se tornou professora da Educação Infantil e quais os elementos que constituíram seu processo identitário nesse período. Com efeito, as experiências de práticas de ensino vivenciadas por Bia durante a formação inicial influenciaram diretamente o seu processo de tornar-se professora da Educação Infantil, como também na inserção profissional, aspecto discutido na subseção a seguir.

\section{INSERÇÃO PROFISSIONAL DOCENTE NA EDUCAÇÃO INFANTIL}

A entrada na carreira é caracterizada como a primeira fase do ciclo de vida profissional dos professores, a qual perdura até os três primeiros anos de exercício profissional, sendo marcada pela sobrevivência e descoberta, perpassada pela exploração das situações de ensino (HUBERMAN, 2007). Sobre esse assunto, os autores Vaillant e Marcelo (2012, p. 124) afirmam que "a inserção à docência é um período intensivo de tensões e aprendizagens [...]", em que o professor novato precisa desenvolver sua identidade docente. Nessa direção, percebemos que a professora entrevistada de fato vivencia esses aspectos que a literatura aponta, com suas singularidades e nuanças.

Refletindo sobre o seu primeiro ano de inserção profissional, Bia revelou que se sentia insegura nesse encontro inicial com o exercício docente. Afirmou que enfrentou dificuldades devido à falta de experiência docente, de recursos, de acolhimento, acompanhamento pedagógico e apoio institucional mais próximo de suas atividades e de conhecimentos científicos específicos para mediar as aprendizagens das crianças com deficiências ou transtornos globais do desenvolvimento, conforme podemos observar no recorte da fala da professora transcrito a seguir.

[...] eu iniciei na Educação Infantil há pouco tempo e tenho apenas três anos de atuação, e assim, como todo início de qualquer outra profissão, tudo sempre é difícil, durante o percurso você encontra algumas dificuldades. [...] a falta de experiência por ser o seu primeiro emprego e com isso você vai aprendendo durante $o$ processo mesmo de sala de aula, aprendendo na prática. [...] no momento inicial é muito importante ter o acolhimento da gestão. Eu me senti por uma parte acolhida, mas por outra não, [...] a gestão não me passou as metodologias e a forma de planejamento, [...] como eu venho de outra cidade, há uma diferença muito grande no planejamento. Então, eu acho que [...] a gestão tem que ajudar o professor nesse sentido. [...] eu tive dificuldade em relação aos recursos porque, por se tratar da rede pública, os recursos são bem escassos. Então, você tem que se virar usando materiais 
reciclados para poder ministrar uma boa aula. [...], por exemplo, trabalhar com crianças especiais; na formação inicial a gente tem algumas disciplinas, mas elas não nos capacitam para trabalhar com crianças especiais, você tem que buscar formação para lidar com essas crianças (PROFESSORA BIA).

O relato da Bia aponta para uma realidade comum no contexto brasileiro: a fragilidade da formação inicial, seja pela desarticulação entre teoria e prática, seja pela fragmentação dos conteúdos didáticopedagógicos, que interfere diretamente no início da docência. É fato que esta formação precisa ser revista e melhorada, especialmente em aspectos que possibilitem um maior contato e reflexão com experiências no contexto do ensino, mas também o período de ingresso na carreira precisa de um apoio e acompanhamento constante, o que deixou a desejar na realidade da Bia. No entanto, destacou que o apoio de algumas docentes mais experientes facilitou a superação de tais dificuldades, aspecto que pode ser identificado como uma das fontes do sentimento de descoberta da profissão vivido por ela. Vejamos: "[...] eu aprendi muito com as minhas colegas de trabalho [...] tive o apoio de professoras que me passaram a forma de planejamento da prefeitura. Elas me auxiliaram e deram opiniões sobre algumas atividades. Eu também fiz muitas pesquisas [...]" (PROFESSORA BIA).

Com seu relato, percebemos que predominou um modelo colegial em sua inserção profissional, no qual, segundo Vaillant e Marcelo (2012), os professores iniciantes pedem ajuda a professores mais experientes, e estes se tornam tutores informais, de maneira espontânea e voluntária, contribuindo para uma inserção profissional mais afetuosa. Considerando que a educação é processual e se concretiza por meio de diálogos (FRANCO, 2016), a professora Bia buscou formar uma rede de apoio, com a troca de conhecimentos e saberes, junto às suas colegas de trabalho, ao reconhecer suas fragilidades e desafios iniciais na profissão docente, e, com isso, aprendeu bastante com seus pares, compartilhando conhecimentos e saberes profissionais.

Para Placco e Souza (2006, p. 20), aprender "[...] supõe aceitar que não se sabe de tudo, ou que se sabe de modo incompleto ou impreciso ou mesmo errado [...]", mas também "[...] relaciona-se ao prazer de descobrir, de criar, de inventar e encontrar respostas para o que se está procurando, para a conquista de novos saberes, ideias e valores" (Idem). Diante desse entendimento, percebemos que a professora Bia compreende a importância da aprendizagem contínua sobre e para a docência e se reconhece como uma profissional incompleta, mas que sempre está em busca de outros conhecimentos por meio de pesquisas e processos autoformativos, que são necessários para o exercício da docência. Além disso, ressaltou a aprendizagem obtida por intermédio de trocas de experiências com os pares, apesar de reforçar a falta de apoio institucional.

$\mathrm{O}$ acolhimento e o trabalho colaborativo marcaram o início da carreira da Bia e contribuíram para a sua socialização e descoberta da profissão, pois, ao sentir-se membra de um corpo profissional, conseguiu aguentar o sentimento de sobrevivência (HUBERMAN, 2007). $\mathrm{O}$ acolhimento dos pares é um ponto importante neste momento da profissão e precisa acontecer de modo intencional e planejado, além das expressões espontâneas. No entanto, é necessário que o professor iniciante receba apoio e orientação de forma sistematizada de modo institucional e como projeto de formação continuada docente, que não dependa da boa vontade de seus pares e gestores educacionais, que é a indução profissional, conforme os estudos de Marcelo Garcia (1999), Alarcão e Roldão (2014), Marcelo et al. (2018) e Nóvoa (2019).

Os processos institucionais de indução profissional docente são elos imprescindíveis que unem a formação inicial ao desenvolvimento profissional ao longo da carreira docente e aumentam as possibilidades de permanência na profissão (MARCELO GARCIA, 1999). Esses processos buscam suprir a carência de experiência dos professores iniciantes por meio de acompanhamento e apoio formal que estabelecem estreita colaboração entre a escola e a instituição de formação inicial. Nesse sentido, a indução profissional docente possibilita que os iniciantes na profissão estejam em contínua formação, adquirindo conhecimentos, atitudes e 
habilidades que os ajudam a melhorar pedagogicamente suas práticas docentes e a superar as dificuldades próprias do início da carreira.

A partir da institucionalização de práticas de indução profissional é possível formar uma completa rede de apoio e de acompanhamento que favoreça o reconhecimento da docência como uma profissão complexa, onde parte da sua aprendizagem ocorre no período de inserção profissional por meio de um aprendizado constante, pois "[...] para enfrentar as questões e os desafios da prática cotidiana é preciso continuar estudando, recorrer a colegas mais experientes, buscar apoio, dispor-se a aprender" (ANDRÉ, 2018, p. 6).

Entretanto, práticas institucionais de indução ainda são escassas e recentes no contexto de inserção profissional. Conforme o relato da docente Bia, podemos constatar que não houve indução profissional no início de sua carreira, pois ela destaca a ausência de orientação da gestão educacional, assim como de apoio sistemático da Secretaria de Educação, aspecto que podemos considerar comum a outros contextos educacionais brasileiros já pesquisados por Gatti, Barreto e André (2011). Nessa pesquisa sobre as políticas docentes em secretarias de educação estaduais e municipais, as referidas autoras constataram a necessidade de um maior apoio para professores em início de carreira e destacaram a importância de planejamento e desenvolvimento de políticas públicas educacionais que favoreçam o acompanhamento dos docentes iniciantes.

No relato da professora iniciante pesquisada, informações como, por exemplo, elaborar o planejamento seguindo a estrutura da rede municipal de ensino de Fortaleza, não lhe foram disponibilizadas pela gestão. A docente encontrou esta necessária orientação junto às suas colegas de trabalho e apontou como dimensão relevante na inserção. Apesar de todas as dificuldades encontradas, a vontade de aprender mais sobre a profissão prevaleceu, levando-a a estar em constante busca de outros conhecimentos e saberes docentes para sua atuação profissional. Ela disse:

[...] depois da minha
formação inicial eu fiz uma
especialização em
$\begin{array}{lr}\text { Educação Infantil, já } \\ \text { pensando no meu } \\ \text { trabalho na parte do }\end{array}$

infantil e futuramente eu pretendo fazer na área da educação especial, pois é uma área que eu acho bem interessante. $\mathrm{Na}$ verdade, eu acho que uma forma de você estar sempre melhorando a sua prática é buscar novas formações. [...] desejo fazer Educação Especial para estar lidando com crianças especiais, porque temos muita demanda de crianças especiais, como a gente não teve formação, porque na formação acadêmica a gente até teve teórica, mas não prática. [...] sempre busco novos conhecimentos, porque como eu falei, vão ter sempre os desafios para serem enfrentados, e não tem como você enfrentar desafios se você não buscar o conhecimento (PROFESSORA BIA).

Diante de tais relatos, evidenciamos na análise que Bia mostrou que tem aprendido bastante com a inserção profissional e que se encontra motivada e instigada a continuar constituindo aprendizagens, tanto investindo na sua autoformação, ao buscar novos conhecimentos em instituições de formação, como a partir dos saberes experienciais "adquiridos e necessários no âmbito da profissão docente e que não provêm das instituições de formação nem dos currículos" (TARDIF, 2002, p. 48-49). Quanto a isso, Pimenta (2009, p. 20) destaca que "[...] os saberes da experiência são também aqueles que os professores produzem no seu cotidiano docente, num processo permanente de reflexão sobre sua prática, mediatizada pela de outrem - seus colegas de trabalho, os textos produzidos por outros educadores".

No que concerne à aprendizagem de adultos, especialmente professores, quando "[...] iniciam na profissão logo após terem concluído a formação inicial, estão em fase de exploração das possibilidades da vida adulta e de início de elaboração de uma estrutura estável de vida" (LIMA et al., 2006, p. 12). Assim sendo, é possível 
perceber que Bia realiza a exploração da docência enquanto sujeito aprendiz na condição de professora iniciante, sempre em busca de estratégias para melhorar a sua prática pedagógica. A seguir, trazemos outro relato da professora que explicita suas aprendizagens docentes com a inserção profissional e o sentimento de descoberta da profissão. trabalhar com eles (crianças que fazem parte do público da Educação Inclusiva e Especial), só que depois você vai conhecendo a criança e vai criando estratégias, por exemplo, o que tem um pré-laudo, eu fui percebendo que ele gosta muito de música, então a acolhida, geralmente eu utilizo música, porque acalma ele, e hoje, por exemplo, recentemente que a gente retornou, eu percebo que ele já chega na sala e não chora mais, porque ele inclusive nem precisa mais da música, porque ele já está ali adaptado com aquele ambiente. [...] Eu acho que a gente tem que sempre buscar novas estratégias para lidar com a família, com a criança, então a gente tem muito que aprender mesmo durante o dia a dia da profissão. Aprendi e ainda falta aprender muito, porque eu acho que três anos é, a experiência em comparação, em relação a outras pessoas que em um tempo de rede, por exemplo, dez anos, não tem nem comparação (PROFESSORA BIA).

As aprendizagens com a prática pedagógica em sala de aula, destacadas por Bia, podem ser percebidas como uma outra fonte do sentimento de descoberta da profissão, que evidenciam o "entusiasmo inicial, a exaltação por estar, finalmente, em situação de responsabilidade (ter a sua sala de aula, os seus alunos, o seu programa) " (HUBERMAN, 2007, p. 39). Vejamos outro exemplo que revelou seu gratificante sentimento de descoberta da docência: "Eu tinha muito anseio em aprender, porque aprendemos muito com a prática. Então, eu tinha muito desejo em estar em sala de aula para, não só ensinar, mas para aprender com as crianças. [...] eu acho que quanto mais experiência temos em sala de aula, aprendemos mais [...]" (PROFESSORA BIA).

Com esse relato, a professora Bia também manifestou reconhecer a importância da relação professor-aluno para sua aprendizagem da docência, valorizando a mediação das crianças para a constituição dos saberes da experiência, aspecto que corrobora os estudos de Tardif (2002) e Pimenta (2009) sobre o fato dos discentes estimularem aprendizagens em seus professores e, com isso, favorecem a elaboração dos saberes da experiência, sendo a relação professor-aluno identificada como um campo de formação permanente, onde essa relação desencadeia uma ação comunicativa entre esses sujeitos no cotidiano educacional e possibilita aprendizagens contínuas para ambas as partes.

Além da literatura sobre o ciclo de vida dos professores conceber Bia como uma professora iniciante, uma vez que ainda está na fase de entrada na carreira (HUBERMAN, 2007), é importante destacar que ela também se considera dessa forma, reconhecendo que está aprendendo a ser docente nesse período de inserção profissional e que continuará aprendendo durante o exercício do magistério. Tal percepção favorece sua aprendizagem da docência nesse período, pois, ao reconhecer que está em formação - desenvolvendo-se profissionalmente de forma contínua em sua prática pedagógica, por meio da reflexão sobre ela, da troca de conhecimento e de experiências com seus pares e da autoformação na qual se materializa por sua busca pessoal permanente por formação e constituição de outros conhecimentos -, consegue encontrar estratégias para superar dificuldades e desafios dessa fase e assim sobreviver ao choque com a realidade expresso na descoberta da profissão. A docente pesquisada destacou que:

Em algumas vezes, eu cheguei em casa e pensei: será se é isso que eu quero para minha vida? Mas depois eu fui criando estratégia de como lidar 
com eles, e fui tendo controle dessas situações. [...] Eu fui dando tempo, vendo mesmo como é que as crianças se comportavam naquele período de adaptação e criando estratégia para facilitar aquele período deles de adaptação, criando brincadeiras que envolvessem eles, que eles se sentissem seguros naquele ambiente [...]. Eu acho que, nesse percurso de professora, você termina realmente errando sim, em muitas coisas, usando uma metodologia, uma atividade que às vezes você percebe que não é adequada, que a criança não está tendo interesse, e a partir do momento em que a gente reflete sobre, do que não está dando certo, a gente passa a utilizar de novas formas, novas metodologias, novas estratégias para atingir o que a gente deseja. [...] eu sempre cheguei em casa e procurei fazer uma reflexão de tudo que tinha dado certo naquele dia e de tudo que tinha dado errado e de buscar mesmo está perto daquelas coisas que deram errado para tentar melhorar minha prática. [...] hoje em dia essa aprendizagem que eu tive lá no primeiro ano fez toda, faz toda diferença hoje, porque hoje eu me sinto mais segura para falar com os pais, lidar com as crianças, com a gestão, então fez toda a diferença (PROFESSORA BIA).

Diante desse relato, a docente Bia revelou que sua prática docente se transformou em prática pedagógica, pois seu modo de ser e estar na profissão reverbera a formação de um profissional crítico e reflexivo que renuncia à consciência ingênua de seu trabalho. Com efeito, é possível afirmarmos que a professora iniciante busca desenvolver uma prática pedagogicamente fundamentada, uma vez que sua postura profissional revela a consciência de suas intencionalidades pedagógicas, suas reflexões críticas, seu compromisso com o trabalho, sua responsabilidade social e suas preocupações com as aprendizagens dos alunos, mesmo sem possuir o devido apoio e condições institucionais adequadas (FRANCO, 2016).

Por intermédio de reflexões sobre sua prática e aprendendo com a experimentação inicial da profissão, a docente Bia vivenciou a responsabilidade de desenvolver estratégias pedagógicas que a conduziram a superar os desafios encontrados na sua iniciação profissional e ajudaram a determinar a sua permanência na carreira docente. $\mathrm{Na}$ subseção a seguir, continuaremos a discussão sobre o início de sua carreira profissional, enfatizando algumas das especificidades da docência na Educação Infantil e os motivos que impulsionam o interesse e a motivação em permanecer na profissão.

\section{ESPECIFICIDADES DA DOCÊNCIA NA EDUCAÇÃO INFANTIL E A PERMANÊNCIA NA PROFISSÃO}

$\mathrm{Na}$ subseção anterior, apresentamos as perspectivas da professora entrevistada sobre a sua inserção profissional e discutimos, com base na literatura sobre o assunto, os desafios e aprendizagens que marcaram seus sentimentos de sobrevivência e descoberta da profissão docente. Deste modo, nesta subseção, trataremos de algumas singularidades da docência na Educação Infantil, com base em Oliveira-Formosinho (2002), inter-relacionando essa discussão e análise de dados com outras contribuições teóricas. Para a autora supracitada, - magistério na Educação Infantil pode apresentar alguns aspectos semelhantes ao magistério nas demais etapas, mas possui especificidades que o diferencia em função das características próprias dos bebês, crianças bem pequenas e crianças pequenas.

Essas características próprias das crianças atendidas por essa etapa da Educação Básica requerem do professor a consideração dos aspectos afetivo, cognitivo, social e biológico em suas práticas docentes, de forma indissociável, acarretando a esses profissionais uma multiplicidade de funções, tais como:

a) A amplitude $e$ diversidade de seu papel 
em responsabilizar-se pelas crianças de forma integral, englobando uma profunda interligação entre "educação e cuidados, entre função pedagógica e função de cuidados e custódia" (OLIVEIRA-FORMOSINHO, 2002, p. 47);

b) $A$ necessidade de estabelecer uma rede de interação entre as crianças, os diferentes profissionais das instituições (psicólogos, assistentes sociais, profissionais da saúde, etc.) e as famílias, integrando "desde o interior do microssistema, que é a sala de educação de infância, até a capacidade de interação com todos os outros parceiros e sistemas" (OLIVEIRA-FORMOSINHO, 2002, p. 48);

c) A integração e interação "entre o conhecimento e a experiência, [...] entre os saberes e os afetos", como elementos centrais da sua docência, sustentando que a docência na Educação Infantil ocorre pela "integração do conhecimento e da paixão" (OLIVEIRAFORMOSINHO, 2002, p. 48-49).

Enquanto professores e formadores de docentes da Educação Infantil, também reconhecemos tais singularidades apontadas por Oliveira-Formosinho (2002, p. 48-49) e destacamos que os professores, sejam eles iniciantes ou não, ao assumirem a responsabilidade com a docência na Educação Infantil, enfrentarão diversos desafios em seu cotidiano profissional. No entanto, evidenciamos que, para os iniciantes, esses desafios podem ganhar maiores proporções e intensidades devido às especificidades que permeiam a fase de inserção profissional, aspectos que já discutidos nas subseções anteriores.
Frente ao exposto, consideramos que, para ser professor de Educação Infantil, é necessário ter conhecimentos e habilidades particulares que vão além daquelas construídas na formação inicial e que são singulares a esta docência. Sobre esse aspecto, a docente Bia demonstrou reconhecer as especificidades e a multiplicidade de funções que marcam o exercício de sua profissão no âmbito da Educação Infantil e revelou que sua formação inicial foi escassa em relação aos conteúdos curriculares e às disciplinas com foco na docência e nas características singulares das crianças que são matriculadas nesta etapa da Educação Básica.

Outro aspecto que diferencia a docência na Educação Infantil das docências em outras etapas e níveis de ensino, é o rompimento com o modelo de monodocência ${ }^{4}$, aspecto que consideramos positivo, especialmente para o desenvolvimento profissional de professores que estão iniciando a carreira. No contexto de atuação profissional da docente Bia, as professoras das turmas de Infantil I, II e III da rede municipal de ensino de Fortaleza desenvolvem seu trabalho com auxiliares/assistentes educacionais ${ }^{5}$, algo que é comum em outras instituições públicas e privadas no cenário brasileiro. Essa composição de dois adultos por turma ${ }^{6}$, exercendo, de certa forma, docências compartilhadas, pode favorecer a troca de conhecimentos entre esses dois adultos aprendizes da docência, possibilita a avaliação mútua e a autoavaliação do desempenho docente, e, por fim, mas não menos importante, rompe com a privatização da prática docente que torna o trabalho dos professores individual, solitário e isolado (COCHRAN-SMITH, 2012).

\footnotetext{
${ }^{4}$ Esse termo é utilizado quando um só professor é responsável pelas aprendizagens e desenvolvimentos dos alunos/crianças (FOLQUE, 2018).

${ }^{5}$ No contexto da rede municipal de ensino de Fortaleza, várias assistentes educacionais possuem formação em nível superior no curso de Licenciatura em Pedagogia ou em curso de nível médio na modalidade Normal. Muitas delas possuem também formação lato sensu em cursos de especialização.

${ }^{6}$ É importante destacar que essa composição de dois adultos por turma, apesar se ser relevante para o desenvolvimento profissional das docentes, não condiz com as exigências previstas nos artigos 17 e 22 da Resolução № 002/2010, do Conselho Municipal de Educação de Fortaleza - Ceará, no que concerne à relação da quantidade de crianças por professor (a), considerando que o responsável direto por qualquer agrupamento de crianças é o (a) professor (a) de Educação Infantil. Nesse sentido, fica evidenciado que a composição mais adequada para satisfazer as normas da Resolução № 002/2010 deveria ser dois (duas) professores (as) por turma, não estando incluídos nessa relação os profissionais com carreira de auxiliar/assistente educacional.
} 
Sobre o aspecto de avaliação mútua e troca de conhecimento na relação de trabalho compartilhado com outro adulto, podemos destacar que a docente Bia revelou ter vivenciado tais experiências durante a sua narrativa, tanto na sua inserção profissional, por meio do relacionamento com a assistente, quanto na sua experiência de estagiária/auxiliar. Segue o relato em que a professora Bia descreve aspectos do seu relacionamento com a auxiliar/assistente educacional.

$$
\begin{aligned}
& \text { [...] em relação à } \\
& \text { assistente, por eu estar } \\
& \text { iniciando ali, no início, eu } \\
& \text { acho que ela até pensou } \\
& \text { assim: nossa, essa } \\
& \text { professora não vai dá } \\
& \text { conta. Mas depois ela foi } \\
& \text { percebendo que eu tinha } \\
& \text { uma boa prática, que eu } \\
& \text { fazia as minhas coisas com } \\
& \text { dedicação. Então, no início } \\
& \text { pode ser que ela tenha } \\
& \text { tido uma imagem de mim } \\
& \text { que depois ela passou a } \\
& \text { ter outra. [...] eu sempre } \\
& \text { fui uma pessoa muito } \\
& \text { aberta, sempre fui uma } \\
& \text { pessoa que nunca tive } \\
& \text { dificuldade em } \\
& \text { relacionamento com } \\
& \text { outras pessoas, eu acho } \\
& \text { que, por exemplo, eu } \\
& \text { tinha uma boa relação } \\
& \text { com a assistente que } \\
& \text { trabalhava comigo } \\
& \text { (PROFESSORA BIA). }
\end{aligned}
$$

Ressaltamos a relevância de ser constituída uma relação de confiança e de parceria, especialmente entre professora e auxiliar/assistente educacional, que conduz a uma melhor atuação profissional e aperfeiçoamento contínuo das práticas pedagógicas (CARDOSO, 2013), o que reflete diretamente no desenvolvimento das crianças. Percebemos que, apesar de no início a auxiliar/assistente educacional ter sentido receio quanto à atuação da docente $\mathrm{Bia}$, com a convivência diária elas estabeleceram, de certo modo, relações de companheirismo e de colaboração, situação importante para a profissão docente na Educação Infantil.

Em relação a sua experiência de estagiária/auxiliar de sala, na qual dividia a responsabilidade de cuidar e educar crianças em turmas de Infantil III e IV em uma instituição privada de ensino, localizada no estado em que morava antes de mudar-se para o Ceará, a professora Bia destacou a importância desse período para sua formação, relatando que as aprendizagens adquiridas (da e sobre a docência) a ajudaram no início da sua inserção profissional, sendo relevantes para o trabalho pedagógico que hoje desenvolve. A seguir, apresentamos alguns trechos de sua narrativa que desencadearam as reflexões anteriores. A professora destacou que:

Eu acho que a forma em como você vai lidar com a criança da Educação Infantil, porque há uma diferença. Na Educação Infantil você tem que [...] ter calma né para lidar com as crianças, isso eu aprendi no período de estagiária. [...] a questão do trabalho com crianças especiais. Como eu já tinha trabalhado com crianças especiais no meu período de estágio, então tiveram algumas coisas que eu aprendi como lidar, outras eu busquei estudando e pesquisando (PROFESSORA BIA).

Como podemos observar nos relatos anteriores, a experiência da docente Bia, enquanto estagiária, proporcionou aprendizagens para sua prática profissional docente, pois possibilitou a aquisição de conhecimentos e habilidades específicas da docência na Educação Infantil e favoreceram sua inserção profissional. Em adição, sobre sua permanência na docência e na Educação Infantil, afirmou que pretende continuar exercendo o magistério nessa mesma etapa e no serviço público, pois não se identifica com o Ensino Fundamental, e relatou preferência pela rede pública em detrimento da rede privada, argumentando que aquela possibilita uma melhor organização do trabalho pedagógico, conforme podemos observar no relato a seguir.

Eu acho que continuar na rede pública, porque na rede privada você vê que o professor termina sendo mais sugado ainda, ele não tem esse tempo de planejamento que a gente tem no público, às vezes 


\begin{abstract}
tem que fazer planejamento em casa, que a gente também como no público às vezes termina levando muitas coisas para casa, mas não se torna tão cansativo como na rede privada [...], mas eu prefiro estar na pública porque você tem um tempo de planejamento para organizar as suas atividades (PROFESSORA $B I A)$.
\end{abstract}

Diante desse excerto, percebemos que o fato que desperta e fortalece seu interesse em permanecer no ensino público é a jornada de trabalho de um terço destinada às atividades extraclasse concedida pela Lei n. 11.738, de 16 de julho de 2008, que instituiu o piso salarial dos profissionais do magistério público da Educação Básica (BRASIL, 2008). No contexto da rede municipal de ensino de Fortaleza no âmbito da Educação Infantil, esse período da jornada de trabalho sem interação com os alunos é destinado para estudo e planejamento de suas aulas, no qual os professores podem, dentro do ambiente educacional, sistematizar suas aulas, fazer relatórios e preencher fichas de avaliação e diários de classe, período esse que não é disponibilizado na rede privada de ensino.

Por fim, a professora entrevistada destacou que investe em sua autoformação, pois o seu interesse de continuar aprendendo a impulsiona na busca pessoal por novos conhecimentos que agreguem sua atuação profissional. Além disso, fez uma reflexão sobre como era a professora Bia no primeiro ano de inserção profissional, como é atualmente e como se vê daqui a dez anos de exercício da docência. Ela disse:

Em relação a quem estava lá no primeiro ano para quem está no terceiro [...], posso dizer que já adquiri experiência, mas ainda há muito que aprender, muito! Me vejo hoje como uma professora excelente [risos]. Assim, eu me vejo hoje uma pessoa diferente, eu sempre estou buscando novas estratégias, sempre quando eu tenho um desafio em sala de aula eu não entro em desespero, eu vou lá e busco estratégias tanto com os familiares, de como está lidando com as crianças, como também estudando, para poder lidar com esses desafios que na verdade vão sempre acontecer em sala de aula. Desejo que daqui a dez anos eu esteja ainda buscando novas formações, porque às vezes você tem um período de formação, de experiência na sala de aula, mas você está naquela mesma prática, usando aquela mesma metodologia, a mesma estratégia, não buscando coisas novas. Então, quando eu tiver com dez anos, desejo que eu tenha sempre esse prazer em buscar novos conhecimentos. [...] Eu não quero ser uma professora acomodada. Quero ser uma professora que estará buscando novas práticas para melhorar o meu trabalho em sala de aula, pois ser professor é um trabalho que requer isso, que você esteja sempre se atualizando (PROFESSORA BIA).

A análise dos dados anteriores nos possibilita evidenciar que o sujeito que aprende, ou seja, o adulto professor indubitavelmente, pautados em Placco e Souza (2006, p. 20), é "aquele que está inserido em processo de formação para a docência, inicial ou contínua, em qualquer fase da carreira e dentro de ampla faixa etária, tendo como característica a exploração proposital da docência, explícita e/ou potencial". Nessa direção, diante dos relatos, percebemos que a professora Bia compreende a aprendizagem da docência como um processo permanente, considerando-se, portanto, um aprendiz ao longo da profissão docente, dimensões essas que são de extrema relevância 
para fortalecer e consolidar também $\mathrm{o}$ desenvolvimento profissional docente.

\section{CONCLUSÕES}

$\mathrm{O}$ estudo realizado problematizou e analisou aprendizagens, desafios e implicações da inserção profissional docente para a formação e prática pedagógica de uma professora da Educação Infantil da rede municipal de ensino de Fortaleza - Ceará. Os resultados desta pesquisa evidenciaram que a inserção profissional docente, compreendida como o período inicial de ingresso na profissão, consiste em uma fase complexa e crucial para a constituição da identidade, permanência na carreira e para o desenvolvimento profissional de professores iniciantes, precisando ser efetivada de modo planejado e não aleatório e espontâneo, em virtude de sua relevância para o sucesso e permanência na docência, pois isso repercute no êxito da prática pedagógica.

Com suporte na narrativa da professora entrevistada, identificamos que as aprendizagens mobilizadas por ela partiram expressivamente das iniciativas autoformativas, das interações com pares e das experiências na prática pedagógica. Tais aprendizagens contribuíram de forma significativa para a formação e a ação pedagógica da professora e favoreceram o seu processo de inserção na carreira docente.

Em relação aos desafios enfrentados pela professora no início da profissão, a investigação revelou que ela vivenciou simultaneamente os sentimentos de sobrevivência e descoberta da profissão, apontados pela literatura apresentada e discutida neste artigo. Esses resultados sinalizam a necessidade de serem desenvolvidos estudos posteriores sobre esse viés investigativo para ampliar o debate e a compreensão acerca da docência na Educação Infantil, em virtude da relevância e necessidade de fazer avançar os estudos sobre essa docência.

Além disso, os resultados evidenciaram que a professora sentiu o impacto da multiplicidade de funções que caracterizam a docência na Educação Infantil e a diferencia das docências em outras etapas e níveis de ensino, aspecto que intensificou os desafios de sua inserção profissional docente e revelou fragilidades da sua formação inicial, como a ausência de determinados conhecimentos e saberes docentes para trabalhar nessa etapa da Educação Básica, situação que poderá ser melhor articulada com a revisão de Projetos Pedagógicos de Cursos de Licenciatura em Pedagogia para assegurar mais ações formativas de aproximação com as escolas - não somente limitadas aos Estágios -, objetivando amenizar o impacto da fase de inserção profissional e favorecer o rompimento com os modelos de pedagogias transmissivas ou tradicionais, que tanto dificultam a constituição da pedagogia participativa (OLIVEIRA-FORMOSINHO, 2002), onde o trabalho pedagógico é pautado na escuta atenta e no olhar sensível às características próprias dos bebês, crianças bem pequenas $\mathrm{e}$ crianças pequenas, atendidas pela Educação Infantil.

Ademais, além dos aspectos comuns às docências em outras etapas da Educação Básica e níveis de ensino, o contato com a professora pesquisada e a análise de seu relato nos permitiu perceber que a docência na Educação Infantil é singular em relação às trocas de afeto e compartilhamento de aprendizagens, mas que também é permeada por desafios e particularidades complexas postas pela função de educar e cuidar de forma indissociável, sobretudo quando se trata de professores iniciantes, situação singular na Educação Infantil. Assim sendo, um acompanhamento ao professor em início de carreira revela ser essencial para que ele possa desenvolver sua prática pedagógica com mais êxito.

Os achados da pesquisa revelaram ainda a inexistência de apoio institucional, que infelizmente é um dos maiores desafios enfrentados pelos professores iniciantes, aspecto que evidencia a relevância e a urgência de planejamento e de implementação de políticas públicas educacionais voltadas especificamente para o acompanhamento sistematizado dos professores em início de carreira. Isso é algo que não necessita ser desenvolvido somente no âmbito da Educação Infantil, mas com todos os docentes que ingressam no magistério, desde a Educação Infantil ao Ensino Superior, destacando maior atenção para a Educação Infantil, em virtude dos aspectos elencados e discutidos neste texto e que revelam o quanto são desafiadores o trabalho e a função de ser docente na primeira etapa da Educação Básica.

Por fim, os dados aqui analisados explicitam a importância das experiências com práticas de ensino durante a formação inicial e a contribuição dessas para a aprendizagem da docência. Com base nessa constatação, concluímos este estudo ratificando a necessidade 
da incorporação de práticas de colaboração entre escola e universidade para promover a articulação entre teoria e prática, com o objetivo de identificar, analisar e suprir possíveis necessidades formativas de professores iniciantes.

\section{AGRADECIMENTOS}

Agradecemos à professora Bia por ter participado desse estudo, narrando o seu processo de inserção profissional na Educação Infantil, compartilhando seus saberes e experiências de professora iniciante e colaborando com a construção de conhecimento acerca do início da docência nessa etapa da Educação Básica, temática que se constitui minoria em relação aos demais estudos sobre essa fase da aprendizagem da docência.

Os autores declaram não haver qualquer potencial conflito de interesse que possa interferir na imparcialidade deste trabalho científico.

\section{REFERÊNCIAS}

ALARCÃO, I; ROLDÃO, M. DO C. Um Passo importante no desenvolvimento profissional dos professores: o ano da indução. Formação Docente - Revista Brasileira de Pesquisa sobre Formação de Professores, Belo Horizonte, v. 06, p. 109-126, ago./dez. 2014. Disponível em: https://revformacaodocente.com.br/index.php/r bpfp/article/view/108/97. Acesso em: 14 ago. 2020.

ANDRÉ, M. E. D. Professores iniciantes: egressos de programas de iniciação à docência. Revista Brasileira de Educação, Rio de Janeiro, v. 23, jul. $2018 . \quad$ Disponível em: https://www.scielo.br/scielo.php?script=sci_abst ract\&pid=S1413-

$24782018000100280 \& \operatorname{lng}=p t \& n r m=i s o \& t \operatorname{lng}=p t$. Acesso em: 30 nov. 2019. DOI: 10.1590/s1413$\underline{24782018230095}$

ASSOCIAÇÃO NACIONAL DE PÓS-GRADUAÇÃO E PESQUISA EM EDUCAÇÃO - ANPED. Ética e pesquisa em Educação: subsídios. Rio de Janeiro: ANPEd, $2019 . \quad$ Disponível em: http://www.anped.org.br/biblioteca/item/eticae-pesquisa-em-educacao-subsidios. Acesso em: 28 out. 2019.

BRASIL. Ministério da Educação. Conselho Nacional da Educação. Resolução CNE/CP № 1, de 5 de maio de 2006. Diretrizes Curriculares Nacionais para o Curso de Graduação em Pedagogia, licenciatura. Brasília: MEC/SEF, 2006. Disponível em: http://portal.mec.gov.br/cne/arquivos/pdf/rcp01 06.pdf. Acesso em: 5 jan. 2020.

BRASIL. Palácio do Planalto. Lei no 11.738, de 16 de julho de 2008. Regulamenta o Ato das Disposições Constitucionais Transitórias, para instituir o piso salarial nacional para os profissionais do magistério público da educação básica. Disponível em: http://www.planalto.gov.br/ccivil 03/ ato20072010/2008/lei/l11738.htm. Acesso em: $10 \mathrm{dez}$. 2019.

BRASIL. Ministério da Educação. Secretária da Educação Básica. Projeto de Cooperação Técnica MEC e UFRS para Construção de Orientações Curriculares para a Educação Infantil. Práticas cotidianas na Educação Infantil: bases para a reflexão sobre as orientações curriculares. Brasília: MEC/SEB/UFRS, 2009a. Disponível em: http://portal.mec.gov.br/dmdocuments/relat se b praticas cotidianas.pdf. Acesso em: 12 jan. 2020.

BRASIL. Ministério da Educação. Conselho Nacional da Educação. Resolução CNE/CP № 05, de 17 de dezembro de 2009. Diretrizes Curriculares Nacionais para a Educação Infantil. Brasília: MEC/SEF, 2009b. Disponível em: http://www.seduc.ro.gov.br/portal/legislacao/RE SCNE005 2009.pdf. Acesso em: 5 jan. 2020.

CARDOSO, S. Professores iniciantes da Educação Infantil: encantos e desencantos da docência. 2013. 157 f. Dissertação (Mestrado Acadêmico em Educação) - Programa de Pós-Graduação em Educação, Universidade Federal de Ouro Preto, Mariana, 2013.

COCHRAN-SMITH, M. Um conto de dois professores: aprendendo a ensinar ao longo do tempo. Kappa Delta Pi Record, v. 48, n. 3, p. 108122, 2012. Disponível em: https://www.tandfonline.com/doi/full/10.1080/0 0228958.2012.707501. Acesso em: 16 dez. 2019. DOI: $\underline{10.1080 / 00228958.2012 .707501}$

FOLQUE, M. A. A formação de educadores/as de infância: da exigência e complexidade da profissão ao projeto de formação na 
UniverCidade de Évora. Poiésis - Revista do Programa de Pós-Graduação em Educação, Niterói-RJ, v. 12, n. 21, p. 32-56, jul. 2018. Disponível em: http://www.portaldeperiodicos.unisul.br/index.p $\mathrm{hp} /$ Poiesis/article/view/6406. Acesso em: $10 \mathrm{dez}$. 2019. DOI 10.19177/prppge.v12e21201832-56.

FORTALEZA. Conselho Municipal de Educação. Resolução $n^{\circ}$ 002/2010. Fixa normas para o Ato de Criação, Credenciamento e Autorização de Funcionamento de Instituições Públicas e Privadas de Educação Infantil no âmbito do Sistema Municipal de Ensino de Fortaleza. Fortaleza: SME/CME, 2010. Disponível em: http://cme.sme.fortaleza.ce.gov.br/index.php/co mponent/content/article/17-uncategorised/5resolucoes. Acesso em: 12 fev. 2020.

FRANCO, M. A. R. S. Prática pedagógica e docência: um olhar a partir da epistemologia do conceito. Rev. bras. Estud. Pedagog, Brasília, v. 97, n. 247, p. 534-551, set./dez. 2016. Disponível em:

https://www.scielo.br/scielo.php?pid=S2176$66812016000300534 \&$ script $=$ sci abstract\&tlng $=p$ t. Acesso em: 06 abr. 2020. DOI: 10.1590/s2176$\underline{6681 / 288236353}$

GATTI, B. A.; BARRETO, E. S. S. Professores do Brasil: impasses e desafios. Brasília, DF: UNESCO, 2009.

GATTI, B. A.; BARRETO, E. S. S.; ANDRÉ, M. E. D. Políticas docentes no Brasil: um estado da arte. Brasília: UNESCO, 2011.

HUBERMAN, M. O ciclo de vida profissional dos professores. In: NÓVOA, A. (Org.). Vida de professores. Portugal: Porto Editora, 2007. p. 3161.

JOVCHELOVICH, S.; BAUER, M. W. Entrevista Narrativa. In: BAUER, M. W., GASKELL, G. Pesquisa qualitativa com texto, imagem e som: um manual prático. Petrópolis Vozes; 2002, p. 90111.

LIMA, E. F. et al. Sobrevivências no início da docência. Brasília: Liber livro, 2006.

LIMA, E. F. A construção do início da docência: reflexões a partir de pesquisas brasileiras. Revista do Centro de Educação (UFSM), Santa Maria, v.29, n.2, p.85-98, 2004. Disponível em: https://periodicos.ufsm.br/reveducacao/article/v iew/3841. Acesso em: 15 dez. 2019.

MARCELO GARCIA, C. Formação de professores: para uma mudança educativa. Portugal: Porto Editora, 1999.

MARCELO, C.; GALLEGO-DOMÍNGUEZ, C.; MURILLO-ESTEPA, P.; MARCELO-MARTÍNEZ, P. Aprender a acompañar: análisis de diarios reflexivos de mentores en un programa de inducción. Profesorado - Revista de currículum y formación del profesorado, v. 22, n. 1, p. 461480, 2018. Disponível em: https://recyt.fecyt.es/index.php/profesorado/arti cle/view/63653. Acesso em: 14 ago. 2020.

MORAES, R. Uma tempestade de luz: a compreensão possibilitada pela análise textual discursiva. Ciência \& Educação, Bauru, v. 9, n. 2, p. 191-211, 2003. Disponível em: https://www.scielo.br/scielo.php?pid=S151673132003000200004\&script=sci arttext\&tlng=pt. Acesso em: 17 jan. 2020. DOI: 10.1590/S1516$\underline{73132003000200004}$

NÓVOA, A. Entre a formação e a profissão: ensaio sobre o modo como nos tornamos professores. Currículo sem fronteiras, v. 19 , n. 1, p. 198-208, jan./abr. 2019. Disponível em: https://www.curriculosemfronteiras.org/vol19iss 1articles/novoa.pdf. Acesso em: 14 ago. 2020.

OLIVEIRA-FORMOSINHO, J. O desenvolvimento Profissional das Educadoras de Infância: entre os saberes e os afetos, entre a sala e o mundo. In: KISHIMOTO, T. M. (Org.). Formação em Contexto: uma estratégia de integração. São Paulo: Pioneira, 2002.

PLACCO, V. M. N. S.; SOUZA, V. L. T. Aprendizagem do adulto professor. São Paulo: Edições Loyola, 2006.

PIMENTA, S. G. (Org.). Saberes pedagógicos e atividades docentes. 7. ed. São Paulo: Cortez, 2009. 246p.

STAKE, R. A arte da investigação com estudos de caso. 4. ed. London: SAGE, 2016.

STAKE, R. Pesquisa qualitativa: estudando como as coisas funcionam. Porto Alegre: Penso, 2011. 
TARDIF, M. Saberes docentes e formação profissional. Petrópolis, RJ: Vozes, 2002.
VAILLANT, D.; MARCELO, C. Ensinando a ensinar: as quatro etapas de uma aprendizagem. Curitiba: Ed. UTFPR, 2012. 